\title{
Monitoramento e caracterização físico-química da matéria orgânica e de enxofre em efluente do tratamento anaeróbio $\begin{array}{ll}\text { Monitoring and physical and chemical characterization of } & \begin{array}{c}\text { Data de entrada: } \\ 28 / 10 / 2020\end{array} \\ 0 \text { organic and sulfur matter in effluent from anaerobic treatment } \\ 04 / 08 / 2020\end{array}$
}

Pedro Ivo Soares e Silva ${ }^{1 * *}$ | Gerlandia Soares Bias ${ }^{2}$ | lasmyn Vasiljevic Mendes Matias Bezerra' | José Tavares de Sousa ${ }^{2}$

DOI: https://doi.org/10.36659/dae.2021.086

ORCID ID

Silva PIS (iD https://orcid.org/0000-0001-6705-2321

Bias GS (iD) https://orcid.org/0000-0003-4447-9001
Bezerra IVMM iD https://orcid.org/0000-0003-0155-2141 Sousa JT (iD https://orcid.org/0000-0002-1056-1771

\section{Resumo}

O estudo tem como objetivo avaliar o tratamento de esgoto doméstico por processo anaeróbio em relação à conversão das frações de enxofre e remoção de matéria orgânica, também considerando as frações de nitrogênio e outros parâmetros. O sistema consiste em um reator anaeróbio UASB convencional, tanque de equalização e filtro de areia com fluxo intermitente. Os resultados mostraram que na primeira fase obteve-se uma remoção de $63 \%$ de matéria orgânica e $77,3 \%$ de turbidez e acréscimo na concentração de sulfeto. Portanto, compreendendo as informações acerca da implantação e da operação, comprova-se a viabilidade do emprego de tratamento anaeróbio combinado com um pós-tratamento para esgoto doméstico.

Palavras-chave: Efluente. Filtro de Areia. Reator UASB. Tratamento.

\section{Abstract}

The study aims to evaluate the treatment of domestic sewage by anaerobic process in relation to the conversion of sulfur fractions and removal of organic matter also considering nitrogen fractions and other parameters. The system consists of a conventional UASB anaerobic reactor, equalization tank and sand filter with intermittent flow. For the results in the first phase, there was a removal of $63 \%$ of organic matter and $77.3 \%$ of turbidity and an increase in the concentration of sulfide. Therefore, understanding the information about the implantation and operation proves the feasibility of using anaerobic treatment combined with a post treatment for domestic sewage.

Keywords: Effluent. Sand Filter. UASB reactor. Treatment.

\footnotetext{
${ }^{1}$ Universidade Federal de Campina Grande - Campina Grande - Paraíba - Brasil.

${ }^{2}$ Universidade Estadual da Paraíba - Campina Grande - Paraíba - Brasil.

* Autor correspondente: pedroivosoaresahotmail.com.
} 


\section{INTRODUÇÃO}

A consciência crescente de que o tratamento de águas residuárias é de vital importância levou à necessidade de desenvolver sistemas que combinam uma alta eficiência a custos baixos de construção e de operação. Ainda assim, os tratamentos dos efluentes devem ser corrigidos e aperfeiçoados de tal maneira que o seu uso ou a sua disposição final possam ocorrer de acordo com a legislação ambiental. Portanto, nas últimas décadas, desenvolveram-se vários sistemas que se baseiam na aplicação da digestão anaeróbia para a remoção do material orgânico de águas residuárias (SILVEIRA FILHO et al., 2018).

Segundo Chernicharo (2007), em reatores anaeróbios ocorrem diversas etapas no processo de digestão anaeróbia, realizada por um consórcio microbiano diversificado. 0 processo acontece devido a uma sequência de ações que são realizadas por um grande e variado grupo de microrganismos, no qual cada grupo realiza uma etapa específica, mas são dependentes das outras. As etapas da digestão anaeróbia são acidogênese, acetogênese e metanogênese, respectivamente, podendo ocorrer a etapa de sulfetogênese.

$\mathrm{Na}$ acidogênese, as bactérias acidogênicas transformam os compostos orgânicos de cadeia simples, geralmente de cadeia curta, em ácidos, cetonas e álcoois (OSTREM, 2004). As concentrações específicas dos produtos formados (ácido butírico, lático, acético e etanol) nessa fase variam com o tipo de bactéria, bem como com as condições de cultura, tais como temperatura e pH (DA SILVA \& DE BORTOLI, 2018).

A acetogênese ocorre por meio da fermentação de hidratos de carbono e resulta em combinação de acetato, $\mathrm{CO}_{2}$ e $\mathrm{H}_{2}$. O papel do hidrogênio como intermediário é de importância fundamental para as reações do processo de digestão anaeróbia. Ácidos graxos de cadeia longa, formados a partir da hidrólise de lipídeos, são oxidados para acetato ou propionato e gás hidrogênio é formado (RAY et. al.,2013).

A metanogênese é o último estágio da decomposição anaeróbia, fase em que o metano é produzido. Esse passo é realizado por microrganismos metanogênicos que são estritamente anaeróbios (PROKOPOVÁ \& PROKOP, 2011). Nesse estágio, as arqueas metanogênicas convertem principalmente o ácido acético, o hidrogênio e o dióxido de carbono em metano. Em função de sua afinidade por substrato e magnitude de produção de metano, as arqueas metanogênicas são divididas em dois grupos principais: as metanogênicas acetoclásticas e as metagonênicas hidrogenotróficas (SCHÖN, 2009).

$\mathrm{Na}$ presença de sulfatos e outros compostos à base de enxofre, a digestão anaeróbia pode incluir ainda a fase chamada de sulfetogenêse, realizada por bactérias sulforedutoras que são capazes de utilizar uma ampla gama de substratos, como hidrogênio e acetato. Dessa forma, passam a competir com as bactérias metanogênicas, reduzindo a produção de metano. O fator limitante para a ocorrência desse processo é a presença de enxofre no meio, que pode estar como sulfato $\left(\mathrm{SO}_{4}{ }^{2-}\right.$ ) ou sulfito $\left(\mathrm{SO}_{2}{ }^{-}\right)$(CHERNICHARO, 2007).

O desempenho de processos biológicos utilizados para tratamento de esgoto depende da dinâmica de utilização de substrato e do crescimento biológico. O projeto e a operação eficaz desses sistemas requerem um conhecimento das reações biológicas que ocorrem e dos princípios básicos que governam o crescimento de microrganismos. Além disso, não pode ser desconsiderado o entendimento das condições ambientais que afetam a utilização de substrato e o crescimento biológico, devendo ser necessário controlar as condições de $\mathrm{pH}$, oxigênio dissolvido e nutrientes para assim proporcionar um tratamento eficaz (METCALF \& EDDY, 2003). 
O tratamento anaeróbio é eficaz ao tratar esgoto doméstico, e o mesmo se torna vantajoso por apresentar baixo custo de implementação, menor produção de lodo e consumo de energia, além de necessitar de uma baixa demanda de área, podendo ocorrer em virtude disso o processo de geração de odores e possível necessidade de um pós-tratamento.

O reator UASB é um dos mais utilizados em decorrência de sua viabilidade técnica, econômica e ambiental. Os reatores UASB possuem facilidades operacionais, hidrodinâmica mais eficiente que outros sistemas convencionais e boa adaptação às condições climáticas do Brasil para diversos efluentes líquidos, além de outras vantagens, como baixo custo de implantação, geração de energia por meio da produção de biogás e pouca geração de lodo (BELLI FILHO et al., 2001; OLMl et. al., 2015).

Segundo Van Haandel et al. (2015), no reator UASB o afluente entra pela parte inferior, seguindo uma trajetória ascendente, passa por uma camada de lodo, sendo depois retirado no topo. Assim, o contato entre o material orgânico do afluente e a massa de lodo no reator é automaticamente garantido. A fim de manter uma massa de lodo elevada, o reator UASB emprega um separador de fases interno, no qual os sólidos suspensos são retidos por sedimentação, para que um efluente virtualmente livre de sólidos sedimentáveis possa ser descarregado.

Os filtros de areia intermitentes são reatores aeróbios de leito fixo que proporcionam a biodegradação ou decomposição do material orgânico contido nos esgotos sanitários, permitindo contato direto entre a massa bacteriana aderida à superfície do meio filtrante e o afluente a ser tratado (de LUNA et al., 2013).

O estudo tem como objetivo avaliar o tratamento de esgoto doméstico por processo anaeróbio em relação à conversão das frações de enxofre e re- moção de matéria orgânica e avaliação do filtro de areia de fluxo intermitente como pós-tratamento de esgoto doméstico.

\section{MATERIAL E MÉTODOS}

\subsection{Localização do sistema experimental}

O sistema experimental foi instalado na Estação Experimental de Tratamento Biológico de Esgotos Sanitários - EXTRABES, da Universidade Estadual da Paraíba - UEPB, localizada em Campina Grande - PB.

\subsection{Sistema Experimental}

Consiste em um reator anaeróbio, UASB convencional representado na Fig. 1 com um tanque de equalização e um filtro de areia com fluxo intermitente. As especificações do reator UASB e filtro estão na Tabela 1. O Filtro de areia possui camada de brita 2 e a granulometria da areia segue os parâmetros estabelecidos pela legislação vigente (ABNT, 1995).

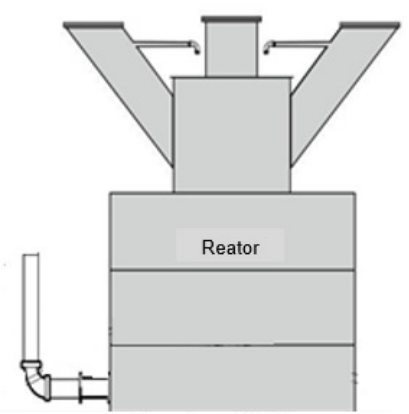

Figura 1 - Sistema Experimental Fonte: Autores (2021)

Tabela 1 - Especificações do Reator UASB

\begin{tabular}{|c|c|c|}
\hline Parâmetros & UASB & Filtro de Areia \\
\hline Volume útil $(\mathrm{L})$ & 175,9 & 1183,0 \\
\hline Altura útil $(\mathrm{m})$ & 1,5 & 0,9 \\
\hline Diâmetro $(\mathrm{mm})$ & 0,4 & 1,2 \\
\hline $\begin{array}{c}\text { Tempo de Detenção } \\
\text { Hidráulica }(\mathrm{h})\end{array}$ & 14 & - \\
\hline Vazão Afluente $\left(\mathrm{L} \mathrm{d}^{-1}\right)$ & 300 & - \\
\hline $\begin{array}{c}\text { Taxa de Aplicação } \\
\text { Superficial }\left(\mathrm{Lm}^{-2} \cdot \mathrm{d}^{-1}\right)\end{array}$ & - & 119,8 \\
\hline
\end{tabular}

Fonte: Autores (2021) 
A pesquisa compreende a instalação, a operação e o monitoramento do reator UASB, assim como do filtro de areia de fluxo intermitente, que estão detalhadas a seguir.

A partir da instalação do sistema, iniciou-se a operação do reator UASB alimentado com esgoto doméstico bombeado de um reservatório de 500 L, com taxa de aplicação de 300 L/d. O efluente foi monitorado em relação aos parâmetros físico-químicos, tendo ênfase na observação do comportamento da matéria orgânica, frações de nitrogênio e enxofre. Objetivando uma estabilização mais eficiente do sistema, foram inoculados $35 \mathrm{~L}$ de lodo anaeróbio com $30 \mathrm{gSSV} / \mathrm{l}$, o que corresponde a $19,8 \%$ do volume útil do reator UASB.

Para o pós-tratamento do efluente oriundo da etapa anaeróbia, iniciou-se a operação do filtro de areia de fluxo intermitente, na qual o efluente do reator UASB é retido no tanque de equalização e através de um sifão é direcionado para o filtro de areia. O filtro operou com $100 \%$ do efluente vindo do tratamento anaeróbio para assim impulsionar o crescimento bacteriano e a formação de biofilme.

\subsection{Acompanhamento e Monitoramento do Sistema}

Foi estabelecido um programa de monitoramento semanal, o qual consistiu na realização de coletas e análises físico-químicas das amostras que seguirão, essencialmente, a disposição do Standard Methods for the Examination of Water and Wastewater (APHA et al. 2012).

Os indicadores de acompanhamento estão definidos na Tabela 2. Quanto à amostragem, foram coletadas no esgoto bruto e no efluente do tratamento anaeróbio e efluente do filtro de areia, possibilitando a caracterização do desempenho do sistema estudado e supervisionar os objetivos da pesquisa.
Tabela 2 - Indicadores de Monitoramento do Sistema.

\begin{tabular}{|c|c|}
\hline Variáveis & Métodos Analíticos \\
\hline DQO & Titulométrico Refluxação Fechada \\
\hline Sulfato & Método Turbidimétrico \\
\hline Sulfeto & Método lodométrico \\
\hline Enxofre Elementar & Método do Cloreto de Bário \\
\hline pH & Potenciométrico \\
\hline Alcalinidade & Kapp \\
\hline Sólidos Suspensos Totais & Gravimétrico \\
\hline Sólidos Suspensos Voláteis & Gravimétrico \\
\hline Sólidos Suspensos Fixos & Gravimétrico \\
\hline NTK & Semi-micro Kjeldahl \\
\hline Nitrogênio Amoniacal & Semi-micro Kjeldahl \\
\hline Turbidez & Nefolométrico \\
\hline \multicolumn{2}{|c|}{ Fonte: Autores (2021) } \\
\hline
\end{tabular}

O nitrito e o nitrato presentes nas amostras foram determinados por Cromatografia de Íons, em um equipamento Dionex - Thermo Scientific, modelo ICS - 1100. A análise estatística dos resultados obtidos durante o estudo foi realizada nos softwares Microsoft Excel e Minitab 19.

\section{RESULTADOS E DISCUSSÃO}

Os resultados das determinações físico-químicas em termos de médias e desvios estão dispostos na Tabela 3, onde EB é referente a esgoto bruto e UASB ao efluente do tratamento anaeróbio.

Tabela 3 - Resultados das análises físico-químicas do esgoto bruto e do efluente tratado no reator UASB.

\begin{tabular}{|c|c|c|}
\hline Parâmetros & $\begin{array}{l}\text { Esgoto Bruto } \\
\text { (EB) }\end{array}$ & $\begin{array}{l}\text { Reator UASB } \\
\text { (UASB) }\end{array}$ \\
\hline $\mathrm{pH}$ & $7,22 \pm 0,18$ & $7,02 \pm 0,29$ \\
\hline Alcalinidade $\left(\mathrm{mgCaCO}_{3} \cdot \mathrm{L}^{-1}\right)$ & $511,45 \pm 56,11$ & $518,37 \pm 60,08$ \\
\hline $\mathrm{AGV}\left(\mathrm{mgHAC} . \mathrm{L}^{-1}\right)$ & $259,05 \pm 47,84$ & $157,50 \pm 71,78$ \\
\hline Turbidez (NTU) & $308,84 \pm 133,72$ & $70,0 \pm 20,90$ \\
\hline $\mathrm{DQQO}\left(\mathrm{mgO}_{2} \cdot \mathrm{L}^{-1}\right)$ & $914,0 \pm 230,02$ & $339,0 \pm 58,06$ \\
\hline SST (mgSST.L-1) & $657,0 \pm 197,54$ & $74,0 \pm 18,14$ \\
\hline SSV (mgSSV.L-1) & $5220 \pm 161,26$ & $57,0 \pm 15,27$ \\
\hline SSF (mgSSF.L-1) & $135,0 \pm 38,66$ & $17,0 \pm 6,74$ \\
\hline Sulfato (mgS-SO $\left.{ }_{4}^{2-} \cdot \mathrm{L}^{-1}\right)$ & $15,20 \pm 4,64$ & $8,84 \pm 5,65$ \\
\hline Sulfeto (mgS-S2-..-1) & $7,69 \pm 5,97$ & $10,47 \pm 3,37$ \\
\hline Enxofre Elementar (mgS-S $\cdot \mathrm{S}^{0}$ ) & $3,25 \pm 0,62$ & $0,91 \pm 0,52$ \\
\hline Amônia $\left(\mathrm{mgN}-\mathrm{NH}_{4} \cdot \mathrm{L}^{-1}\right)$ & $90,97 \pm 14,18$ & $87,75 \pm 8,66$ \\
\hline NTK (mgN-NTK.L-1) & $226,61 \pm 10,92$ & $166,5 \pm 21,75$ \\
\hline Nitrito $\left(\mathrm{mgN}-\mathrm{NO}_{2}{ }^{-} \cdot \mathrm{L}^{-1}\right)$ & $0,42 \pm 0,70$ & $0,27 \pm 0,45$ \\
\hline Nitrato $\left(\mathrm{mgN}-\mathrm{NO}_{3} \cdot \mathrm{LL}^{-1}\right)$ & $0,78 \pm 0,65$ & $0,46 \pm 0,51$ \\
\hline
\end{tabular}


As medidas de $\mathrm{pH}$ variaram entre 7,02 e 7,22, estabelecendo-se na faixa de $\mathrm{pH}$ ótimo para crescimento bacteriano. $\mathrm{O} \mathrm{pH}$ do ambiente é um fator fundamental no crescimento de organismos. A maioria das bactérias não tolera níveis de $\mathrm{pH}$ acima de 9,5 ou abaixo de 4,0. Geralmente, o valor de $\mathrm{pH}$ ótimo para o crescimento de bactéria está entre 6,5 e 7,5 (METCALF \& EDDY, 2003).

A operação do sistema UASB, apesar de simples, pode sofrer influência de aspectos ambientais que alteram as predominâncias desses grupos microbianos (VAN HAANDEL \& LETTINGA, 1994). Para alcalinidade total, houve uma variação de 511,45 a 518,37 $\mathrm{mgCaCO}_{3} \cdot \mathrm{L}^{-1}$, resultando em um aumento de concentração do afluente para o efluente.

Para os ácidos graxos voláteis dados em mgHAC.L-1 , houve uma diminuição de concentração de $39,2 \%$ do esgoto bruto para o efluente. Os intervalos de $\mathrm{pH}$ encontrados nesse estudo cor- roboram os de Lopes et al. (2009), que avaliou os efeitos do $\mathrm{pH}$, alcalinidade e AGV na microbiota de reatores UASB e afirma que nesse intervalo de $\mathrm{pH}$ os ácidos graxos voláteis estavam em sua grande maioria de forma ionizada, sendo assim não tóxicos para as bactérias metanogênicas.

Em relação à turbidez, foi observada uma redução de 77,33\%, onde o efluente anaeróbio obteve 70,0 NTU. Para obter valores mais reduzidos para turbidez, Bakopoulou et al. (2011) afirma que é viável a aplicação de um método de tratamento avançado como filtração em areia, onde o mesmo é tido como essencial antes do processo de desinfecção. Com uma unidade de filtração, além da maior redução dos valores de turbidez também podem-se obter menores valores para os SST.

$\mathrm{Na}$ Fig. 2 tem-se os resultados obtidos na análise de DQO para o afluente e o efluente oriundos do reator UASB.

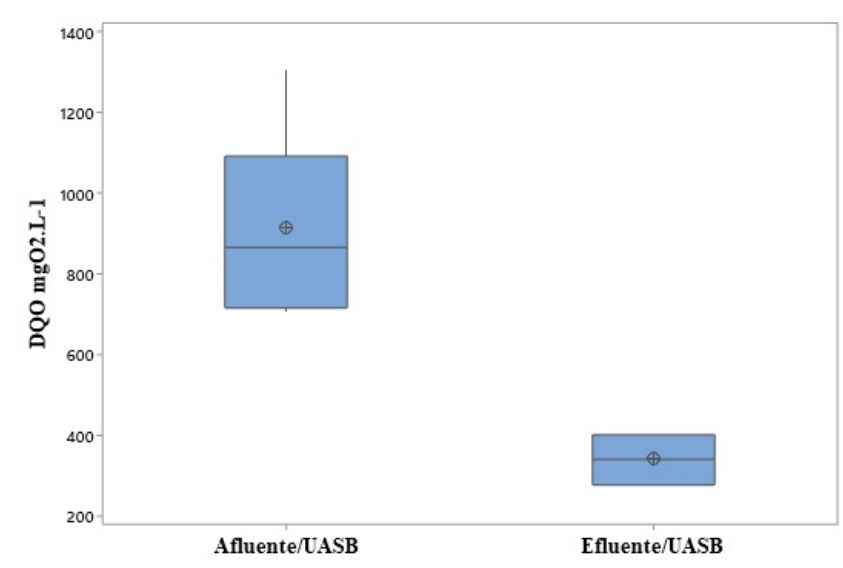

Figura 2 - Resultados de DQQO para afluente e efluente oriundos do reator UASB.

Tratando-se da matéria orgânica, ocorreu a remoção de $63 \%$ de DQO , medida que se adequa aos valores de remoção encontrados na literatura em termos de tratamento anaeróbio (entre 60 e $70 \%$ ).

Assim, para obter uma maior eficiência de remoção de matéria orgânica e como também remoção de nutrientes, o efluente oriundo do processo anaeróbio deve ser submetido a um pós-tratamento. Para a fração de sólidos foram obtidos valores com eficiência de remoção superior a $85 \%$, podendo-se observar a influência da remoção de matéria orgânica para o alcance 
desses resultados. Na Fig. 3 têm-se os resultados para as frações de enxofre.

O tratamento anaeróbio é uma opção de baixo custo, remove de 60 a $70 \%$ de matéria orgânica e produz uma quantidade reduzida de lodo. No entanto, como não produzem um efluente adequado aos padrões legais, os sistemas anaeróbios devem ser vistos como uma primeira etapa do processo, necessitando de um pós-tratamento que complemente a remoção de matéria orgânica, nutrientes e microrganismos patogênicos (CHERNICHARO, 2008).
A decomposição anaeróbia de compostos de enxofre é a principal causa da geração de odores. Dependendo do composto precursor, do $\mathrm{pH}$ e do potencial de oxirredução do esgoto, diferentes compostos odorantes são biologicamente formados, sendo o sulfeto de hidrogênio, resultante da redução biológica do sulfato pelas bactérias redutoras de sulfato (BRS), o composto mais comumente associado aos odores do esgoto, embora outros compostos de enxofre (Ex.: mercaptanas), ácidos orgânicos voláteis, álcoois e amônia também possam contribuir para a percepção dos odores provenientes do esgoto (STUETZ \& FRECHEN, 2001).

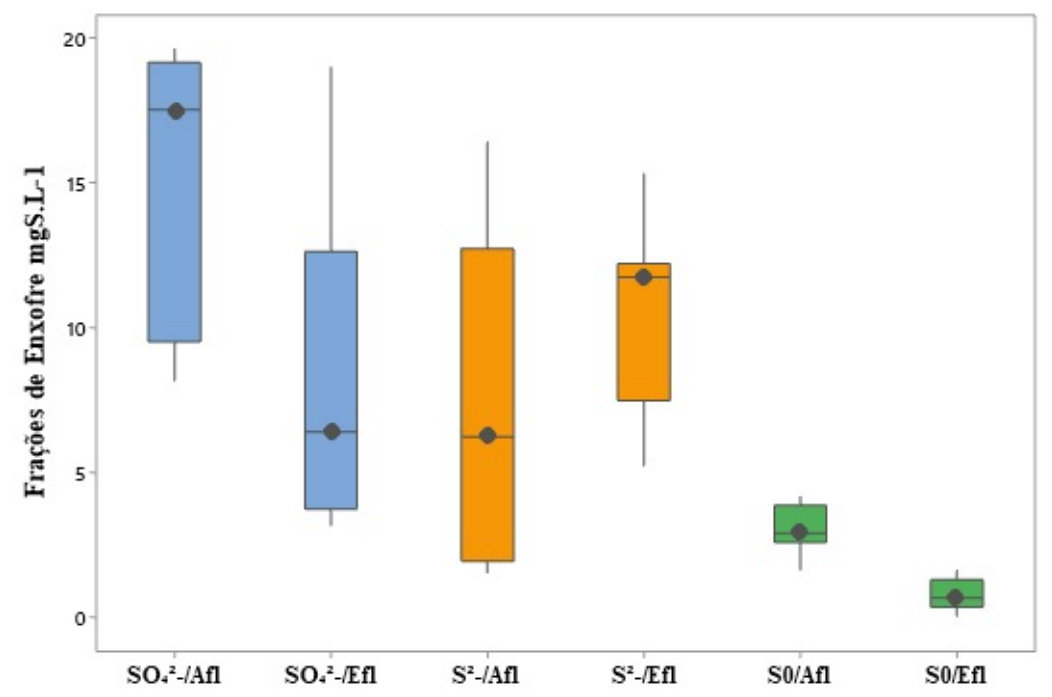

Figura 3 - Resultados das frações de enxofre para afluente e efluente oriundos do reator UASB.

\begin{abstract}
Onde $\mathrm{SO}_{4}{ }^{2-} / \mathrm{Afl}$ é a concentração de sulfato no afluente, $\mathrm{SO}_{4}{ }^{2-} /$ Efl é a concentração de sulfato no efluente, $\mathrm{S}^{2-} / \mathrm{Afl}$ é a concentração de sulfeto no afluente, $\mathrm{S}^{2-}$ /Efl é a concentração de sulfeto no efluente, S\%/Afl é a concentração de enxofre elementar no afluente e $S^{0} /$ Efl é a concentração de enxofre elementar no efluente.
\end{abstract} Fonte: Autores (2021)

Observa-se nos dados de sulfato e sulfeto uma variabilidade nos dados. Isso ocorre porque o afluente utilizado na pesquisa é oriundo de um empreendimento residencial recém-construído onde se tem oscilação em relação ao número de moradores. Além disso, o efluente, antes de ser bombeado para o reservatório de alimentação, fica retido em um tanque onde pode ocorrer a etapa de sulfetogênese antes da alimentação do sistema.

A principal forma de enxofre que adentra o reator de tratamento com o esgoto bruto é o anion sulfato $\left(\mathrm{SO}_{4}^{-2}\right)$. Em condições anaeróbias, as BRSs reduzem compostos orgânicos simples como sulfato e geram sulfeto e alcalinidade, assim houve 
um decréscimo na concentração de sulfato de 15,20 para $8,84 \mathrm{mgS}^{-\mathrm{SO}_{4}}{ }^{2-} . \mathrm{L}^{-1}$.

Os resultados para a determinação de sulfetos indicaram um acréscimo de 7,69 mgS- $\mathrm{S}^{2-} \cdot \mathrm{L}^{-1}$ no afluente para $10,47 \mathrm{mgS}-\mathrm{S}^{2-} \cdot \mathrm{L}^{-1}$ no efluente, esse comportamento já é esperado pelo fato da ação das bactérias redutoras de sulfato e outros compostos de enxofre, que em condições anaeróbias formam $\mathrm{H}_{2} \mathrm{~S}$.

Segundo Bitton (2007), microrganismos assimilam formas oxidadas como também reduzidas de enxofre. Os microrganismos anaeróbios assimilam formas reduzidas, tais como sulfetos; por outro lado, aeróbios utilizam a forma mais oxidada.

Tratando dos resultados de concentração de enxofre elementar, houve uma eficiência de remoção de $72 \%$ sob condições anaeróbias; aminoácidos contendo enxofre são degradados a compostos de enxofre ou a mercaptanas, que são compostos de enxofre odorantes (BITTON, 2007).
Chernicharo (2007) afirma que, em sistemas anaeróbios como UASB, a remoção de nutrientes não é bem-sucedida nessa etapa de pré-tratamento. Sendo assim, não houve remoção significativa em termos de nitrogênio amoniacal na primeira fase do experimento, com valores de $91 \mathrm{mgN}-\mathrm{NH}_{4} \cdot \mathrm{L}^{-1}$ para o esgoto bruto $\mathrm{e}$ $87,7 \mathrm{mgN}-\mathrm{NH}_{4} \cdot \mathrm{L}^{-1}$ para o efluente do reator UASB; para o NTK houve eficiência de remoção de $26,5 \%$.

Em condições favoráveis, o nitrogênio amoniacal será oxidado a nitrito $\left(\mathrm{NO}_{2}^{-}\right)$e posteriormente a nitrato $\left(\mathrm{NO}_{3}{ }^{-}\right)$pelo processo denominado nitrificação, processo essencialmente biológico aeróbio (ASSUNÇÃO, 2009).

Sendo assim, houve remoção de $35 \%$ de nitrito com valores de $0,42 \mathrm{mgN}^{-\mathrm{NO}_{2}}{ }^{-} \mathrm{L}^{-1}$ para o esgoto bruto e $0,27 \mathrm{mgN}-\mathrm{NO}_{2}^{-} \cdot \mathrm{L}^{-1}$ para o efluente do reator UASB e remoção de $41 \%$ para a fração de nitrato com concentração final de $0,46 \mathrm{mgN}-\mathrm{NO}_{3}{ }^{-} \cdot \mathrm{L}^{-1}$. $\mathrm{Na}$ Tabela 4 têm-se os resultados preliminares do filtro de areia de fluxo intermitente

Tabela 4 - Resultados das análises físico-químicas preliminares para EB, UASB e FaFint.

\begin{tabular}{|c|c|c|c|}
\hline Parâmetros & Esgoto Bruto (EB) & Reator UASB (UASB) & Filtro de Areia (FaFint) \\
\hline $\mathrm{pH}$ & $7,03 \pm 0,02$ & $6,96 \pm 0,05$ & $6,85 \pm 0,09$ \\
\hline Alcalinidade $\left(\mathrm{mgCaCO}_{3} \mathrm{~L}^{-1}\right)$ & $465,61 \pm 63,9$ & $458,7 \pm 22,9$ & $422,7 \pm 32,07$ \\
\hline AGV $\left(\mathrm{mgHAC.L}^{-1}\right)$ & $224,6 \pm 56,7$ & $112,34 \pm 12,14$ & $109,41 \pm 5,77$ \\
\hline Turbidez (NTU) & $271,78 \pm 129,35$ & $61,96 \pm 28,08$ \\
\hline
\end{tabular}

Fonte: Autores (2021)

O filtro de areia favorece a adsorção de contaminantes do fluxo do efluente, além de ser de simples operação, pouca manutenção e baixo custo de operação (ALLEN et al., 2010). O sistema de filtro de areia é composto por um tanque de volume variável, areia, brita e em alguns casos carvão mineral. A eficiência do filtro de areia varia de acordo com a taxa de aplicação, com a qualidade do efluente e com a espessura e a granulometria das camadas filtrantes (JUNIOR \& MARTINS, 2016).
Nota-se uma redução de $92 \%$ para o parâmetro de turbidez comparando o esgoto bruto com o efluente oriundo do filtro de areia, o que é considerado satisfatório por se tratar do início da operação do sistema.

$\mathrm{O} \mathrm{pH}$ variou entre 7,03 e 6,85, com medida intermediária de 6,96 para o efluente do reator UASB. $A$ alcalinidade apresentou maior valor para o esgoto bruto com 465,61 $\mathrm{mgCaCO}_{3} / \mathrm{L}$, não ocorrendo geração de alcalinidade do efluente do 
reator UASB para o efluente do filtro de areia. Em termos de ácidos graxos voláteis, ocorreu uma redução de 51,28\%, comparando-se o esgoto bruto com o efluente do filtro de areia.

\section{CONCLUSÕES}

$\mathrm{Na}$ primeira fase do estudo, objetivou-se a caracterização do esgoto bruto e do efluente do reator UASB. Em termos de análises físico-químicas, houve remoção de $63 \%$ de matéria orgânica; para as frações de enxofre houve remoção de $72 \%$ de enxofre elementar; por meio da ação das bactérias redutoras de sulfato ocorreu redução de $41 \%$ na concentração de sulfato e, como esperado, ocorreu produção de sulfeto.

Ocorreu o início da operação do filtro de areia de fluxo intermitente com $100 \%$ de efluente do reator UASB visando ao crescimento microbiano e à formação de biofilme no meio. As análises já realizadas apresentam valores reduzidos de turbidez no efluente do filtro de areia.

Assim, os resultados para matéria orgânica e das frações de enxofre e nitrogênio confirmaram a necessidade do pós-tratamento; uma alternativa viável seria o filtro de areia de fluxo intermitente, possibilitando o tratamento e o pós-tratamento no mesmo local, reduzindo possíveis custos de operação. Os resultados preliminares do filtro de areia de fluxo intermitente confirmam a eficiência do tratamento e possibilitam o tratamento em maior escala.

\section{AGRADECIMENTOS}

Os autores deste trabalho agradecem à FAPESQ, à Capes e à EXTRABES - UEPB pelo apoio concedido para a realização deste estudo.

\section{CONTRIBUIÇÃO DOS AUTORES}

Todos os autores contribuíram de forma igualitária.

\section{REFERÊNCIAS}

ALLEN, L. CHRISTIAN-SMITH, J. \& PALANIAPPAN, M. Overview of greywater reuse: The potential of greywater systems to aid sustainable water management. Inormally published manuscript, Pacific Institute, Oakland, Califórnia, 2010. ISBN: 1-893790-27-4

APHA, AWWA, WEF. Standard Methods for examination of water and wastewater. 22nd ed. Washington: American Public Health Association; 2012.

ASSOCIAÇÃO BRASILEIRA DE NORMAS TÉCNICAS - ABNT. NBR 13.969 - Tanque sépticos - Unidades de tratamento complementar e disposição final dos efluentes líquidos Projeto, construção e operação. Rio de Janeiro, 1997.

ASSOCIAÇÃO BRASILEIRA DE NORMAS TÉCNICAS - ABNT. NBR 6502 - Rochas e Solo. Rio de Janeiro, 1995.

ASSUNÇÃO, F. A. L. Estudo da remoção de nitrogênio, com ênfase na volatilização de amônia, em lagoas de polimento de efluentes de reatores UASB tratando esgotos urbanos de Belo Horizonte/MG. 2009.

BAKOPOULOU, S.; EMMANOUIL, C.; KUNGOLOS, A. Assesdment of wastewater effluent quality in Thessaly region, Greece, for determining its irrigation reuse potential. Ecotoxicology and Environmental, v. 74, p. 188-194, 2011. http://doi.org/10.1016/j. ecoenv.2010.06.022

BELLI FILHO, P.; CASTILHOS JÚNIOR, A. B.; COSTA, R. H. R.; Soares, S. R.; Perdomo, C. C. Tecnologias para o tratamento de dejetos de suínos. Revista Brasileira de Engenharia Agrícola e Ambiental, v.5, n.1, p.166-170, 2001. https://doi.org/10.1590/S141543662001000100032

BITTON, G. Wastewater Microbiology. 3 ed. John Wiley \& Sons, Inc, 2005. ISBN: 978-0-471-71791-1

CHERNICHARO, C. A., STUETZ, R. M., SOUZA, C. L., de MELO, G. C. B. Alternativas para o controle de emissões odorantes em reatores anaeróbios tratando esgoto doméstico. Eng Sanit Ambient, 15(3), 229-236, 2010. https://doi.org/10.1590/S141341522010000300005

CHERNICHARO, C. A. Princípios do tratamento biológico de águas residuárias: Reatores anaeróbios. $2^{\mathrm{a}}$ ed. Belo Horizonte: Departamento de Engenharia Sanitária e Ambiental-DESA/ UFMG, Editora UFMG, 2007.

DA SILVA, M. I., \& DE BORTOLI, A. L. Modelagem e simulação do processo de formação do biogás. Proceeding Series of the Brazilian Society of Computational and Applied Mathematics, 6(1), 2018. https://doi.org/10.5540/03.2018.006.01.0391 
JUNIOR, R. M., \& MARTINS, M. V. L. Dimensionamento de filtro de areia para tratamento de água cinza do bloco novo do IRN. Revista Brasileira de Energias Renováveis, 5(3), 2016. http:// dx.doi.org/10.5380/rber.v5i3.48130

LOPES, E. P.; CAMPOS, C. M. M. \& MOTERANI, F. Efeitos do pH, acidez e alcalinidade na microbiota de um reator anaeróbio de manta de lodo (UASB) tratando efluentes de suinocultura. Ambiente \& Água-An Interdisciplinary Journal of Applied Science, 4(3), 2009. https://doi.org/10.4136/AMBI-AGUA.109

OLMI, V. R., PIRES, A. M. B., RAMOS, A. D. L. S., KAMEYAMA, O., de MANCILHA, I. M., \& Passos, F. J. V. UASB/evaluation of the behavior of a synthetic media and swine wastewater in the anaerobic treatment of UASB reactors. Ceres, 53(307), 2015.

OSTREM. K. Greening Waste: Anaerobic Disgestion for Treating the Organic Fraction of Municipal Solid Wastes. Tese (Doutorado em Engenharia e Ciências Aplicadas), Columbia University, 2004.

PROKOPOVÁ, Z. and PROKOP, R. Modelling and simulation of dry anaerobic fermentation. European Conference on Modelling and Simulation, 200-205, http://doi.org/10.7148/2010-02000205, 2010.

RAY, N. H. S.; Mohanty, M. K.; and Mohanty. R. C. Anaerobic digestion of kitchen wastes: "biogas production and pretreatment of wastes, a review". International Journal of Scientific and Research Publications, 3: 2250-3153, ISSN 2250-3153, 2013.

SCHÖN, D. I. M. Numerical Modelling of Anaerobic Digestion Processes in Agricultural Biogas Plants. Dissertação, Innsbruck, Februar, 2009.

SILVEIRA FILHO, A. S. L., MENSAH, J. H. R., DE MELLO BATTISTON, K., BARROS, M. S., \& DOS SANTOS, I. F. S. Dimensionamento de um reator UASB para tratamento de efluentes domésticos e recuperação do biogás para produção energética: Um estudo de caso em Pouso Alegre (MG). Revista Brasileira de Energias Renováveis, 7(1), 2018. https://doi.org/10.21438/rbgas.061402

STUETZ, R.M. \& FRECHEN, F.B. Odours in wastewater treatment: measurement, modelling and control. Londres: IWA Publishing. 456p, 2011.

VAN DER ZEE, F.P.; VILLAVERDE, S.; GARCÍA, P.A.; FDZ-POLANCO, F. Sulfide removal by moderate oxygenation of anaerobic sludge environments. Bioresource Technology, v. 98, p. 518-524, 2007. https://doi.org/10.1016/j.biortech.2006.02.011

VAN HAANDEL, A. et al. Influência do projeto do separador de fases sobre o desempenho do reator UASB no tratamento de águas residuárias municipais. Revista DAE. Set-Dez, p. 64-75, 2015. http://dx.doi.org/10.4322/dae.2014.153 